\title{
Remodelling and Rehabilitation of Irrigation Outlets in Water Distribution of Canals in Punjab, Pakistan
}

\author{
Talat Farid Ahmed ${ }^{1 a}$, Hashim Nisar Hashmi ${ }^{2}$, Ashfaq Ahmed Sheikh ${ }^{3}$, \\ Muhammad Attiqullah Khan ${ }^{1 \mathrm{~b}}$, Muhammad Azeem Afzal ${ }^{1 \mathrm{c}}$
}

RECEIVED ON 10.01.2019, ACCEPTED ON 05.05.2021

\begin{abstract}
This paper highlights the problems associated with the outlets in the irrigation system of Pakistan, leading to the design of outlets, to trace the gradual evolution of various outlets types and to describe most of the types that have been evolved so far. The advantages and limitations of each type have been examined critically so that the selection of a type for any particular set of conditions may be rendered easy. An outlet is a flow measuring and controlling device between farmer's land and an irrigation system. In Punjab about fifty thousand outlets irrigate an area of approximately 25.5 million acres annually. Improperly designed outlets may cause a number of problems such as variation in their coefficients of discharge, inequitable distribution of water, silting of canals, inadequate availability water at the lowest outlets, lack of incentives for saving of water and poor drainage. Field calibration of the irrigation outlets proved that their calibrated Cd. vary from the designed Cd. (0.6 for OF \& 0.9 for AOSM), as outlets were not designed according to their designed parameters. Defective outlets were also the main cause of silting in canals. The pipe-cum-semi module was very helpful to draw silt from the bed of the parent channel in a case if we want a higher setting of outlet. $20 \%$ of canal water in Rabi season and $40 \%$ water in Kharif season were snatched by illegally Theft problem. In order to prevent theft, the outlets should be tamper proof and the irrigation department should adopt the legal procedure strictly. All over the world, the engineers and farmers designed and installed various kinds of farm outlets suiting their local conditions. Work is being carried out to make them structurally, hydraulically and economically fit. An attempt is made to bring all the information together leading to economical and efficient design of outlets and to look upon their possibility of adaptability in Pakistan.
\end{abstract}

Keywords: Irrigation outlets, Canal water, Silting, Irrigated region

\section{INTRODUCTION}

$\mathrm{E}$ conomy of Pakistan is based on Agricultures Sector that contributes $25 \%$ of the Gross Domestic Product (GDP) and absorbs $50 \%$ of the total labour force of the nation. About $60 \%$ of the territory, however, including main crop production area of Sind and Punjab belongs to the dry region where annual rainfall is less than $250 \mathrm{~mm}$. Irrigation is very important for the crop production and Pakistan is the distinguished irrigated country in the world having 16 million hectares of irrigated land that is equivalent to $20 \%$ of the territory of 800,000 square $\mathrm{km}$ or $76 \%$ of cultivated land consequently. The major target is to maximize effective use of limited water for irrigation.

The main test parameter of a properly designed irrigation system is the uniform distribution of water among all areas. This distribution is controlled and carried out via a hydraulic structure known as Outlet;

\footnotetext{
${ }^{1}$ National Agriculture Research Centre, Park Road, Islamabad, Pakistan.

Email: atafa367@gmail.com (Corresponding Author), batiq939@yahoo.com, aaeemafzal42@gmail.com

${ }^{2}$ Department of Civil Engineering, University of Engineering and Technology, Taxila.

Email: hashim.nisar@uettaxila.edu.pk

${ }^{3}$ Pakistan Engineering Council, Islamabad, Pakistan. Email: drashfaq@ @ec.org.pk
}

This is an open access article published by Mehran University of Engineering and Technology, Jamshoro under CC BY 4.0 International License. 
therefor their design has maximum impact on equitable distribution of water. The outlet is a pivotal structure in irrigation network and plays a key role in proper distribution of the natural gift. The irrigation system in Pakistan is laid on a very mild slope and is upstream controlled further it is supply based and is not demand base because of low quantum of available water. Therefore, outlet is only point at which the water can be measured/ controlled and delivered to the farmers.

There are three types of outlets based on principal. Which are; Modular outlet or Rigid Module which has independent discharge of the water levels in the distributary in reasonable working limits, SemiModular outlet in which has independent discharge of water level in the water course but dependent on the water levels in the distributary so long as the minimum working head required for its working is available and Non- modular outlet in which the discharge depends on the water level difference in the supply canal and watercourse. This means that a cultivator can get illegal benefits by more discharge of water by lowering the water level in the water course.

Indispensable requirements for any type of outlet are based on their Flexibility, Sensitivity, Efficiency, Minimum Modular Head, Coefficient of Discharge, Silt drawing capacity, Adjustability and Immunity from Tampering. These parameters facilitate the assessment of performance of an outlet. In this study, the outlet problems validity of existing formulae and their improvement was done in the existing equations in the light of experimental results, which in turn helpful in; Enhancing irrigation supplies in the area, improving the economic condition of the area and Ensuring maximum use of canal water for increase of agricultural production.

To assess the water delivery performance of the Som Kamla Amba irrigation scheme in Dungarpur district of Rajasthan was carried out with indicators like adequacy, equity and dependability. For these three minors each at the head, mid and tail sections of main canals (Right and Left Main Canal) and branch canals (Aspur Branch Canal and Baroda Branch Canal) were selected. The ratio of water delivered (obtained from discharge measured at outlets) and water required (calculated from CROPWAT software) was determined for major rabi crops (wheat, barley, gram and mustard) grown in the command area in one year. It was found that Results were good (1.00 to 0.93), fair (0.84 to 0.80$)$ and poor ( 0.42 to 0.18$)$ adequacy at the head, mid and tail sections of each canal respectively and poor equity in water delivery as its value varied from 0.35 to 0.92 . The Dependability was found to be good at head, fair at mid and poor at tail sections [1].

A strategic analysis of the water delivery service to understand whether a better water allocation is possible in collective irrigation systems by implementing improving measures at lower cost compared to structural works was initiated in Italy. For this, performance of three water delivery systems was evaluated over four irrigation seasons, using the indicators of adequacy, efficiency, dependability and equity developed by Molden and Gates [2]. Then, three scenarios for improving irrigation management (replacement of sprinkler methods with microirrigation, an arranged-demand water delivery service together with an irrigation advisory service, and a combination of both actions) were simulated and evaluated. In addition to that two new indicators ("User Satisfaction Index" and "Water Exploitation Index"), measuring satisfaction of irrigation service users and water use levels, were proposed and applied. The results revealed that current situation poor adequacy, reliability and equity of water delivery service with low user satisfaction together with fair efficiency in exploiting the limited irrigation resources. The simulation of an arranged-demand distribution and irrigation advisory service was found to be more efficacious and favourite to the system users than the replacement of current sprinkler systems with micro-irrigation. They suggested combined adoption of these scenarios to assure the optimal performance in water delivery systems and to make the collective service more adequate and efficient for both irrigation users and managers [2].

A study was initiated by using a cluster of fields for design of underground pipe distribution network (PDN) along with controllable turnout structures to improve WUE and to save land taken up by canals instead of canal distribution network $(\mathrm{CDN})$ in the irrigation command area. Eight numbers of outlets were proposed in the design of PDN. The outlets 
deliver water to a diversion box of $45 \times 45 \times 45 \mathrm{~cm}$. Two outlets of $20 \mathrm{~cm}$ diameter were proposed in each diversion box, one for right hand side of fields and other for left side fields for delivering irrigation water directly to the farmer's fields. A $20 \mathrm{~cm}$ diameter pipe was found suitable for delivering water till the end of PDN with bed slope of $0.8 \%$. The head loss was found $2.63 \mathrm{~m}$, less than that of available head of $4.77 \mathrm{~m}$. Air vents of $5 \mathrm{~cm}$ diameter were also provided at appropriate points to release entrapped air. With the Adoption of PDN, reduction in water conveyance/distribution losses, reduction in the land area, reduction in the maintenance and operating costs of the irrigation system were found significantly [3].

A study was initiated to compare economic aspects of Pipe Distribution Network (PDN) over Canal Distribution Network (CDN) by optimal utilization of water. They suggested that it can be improved to 70$80 \%$ by PDN as it was $25-40 \%$ in CDN.so PDN is more economical and feasible than CDN [4].

A research was conducted to evaluate the performance of command area of left main canal of Bhimsagar irrigation project; Rajasthan. Outlet-wise performance was evaluated with parameters like adequacy, equity, dependability, relative irrigation supply and relative water supply. The 21 outlets located on three minors at head, middle and tail reach of the left main canal were used for parameter evaluation under 5-month irrigation period during Rabi season, using measured water deliveries and calculated crop water requirements. It was found that the outlet-wise water delivery performance indicators showed poor performance of the system. Considering the irrigation season and the system as a whole, the average value of indicators were found as "poor" for adequacy, equity and dependability; emphasizing for adopting improved management strategies [5].

A study was initiated to know water delivery efficiency in irrigation canals using performance indicators that is essential for detecting the key issues for water management improvement. For this irrigation efficiencies according to the water delivery performance indicators were measured with an automatic water gauge in the irrigation canals and were calculated from the spatial and temporal distribution of the water supply for the lack of planning in water delivery. It was found that calculated performance indicators were useful to understand the irrigator behavior and general irrigation trends. Analysis of the results yielded insights into possible improvement methods in order to develop water management policies that enable irrigation planners to improve the temporal uniformity and equity in the water distribution [6].

A study was conducted to know the fairness in distribution of water in a tertiary canal within the Indus Basin Irrigation System by using two procedures as canal rating equations and outlet discharge equations. Fairness/equity was expressed quantitatively using the Gini index. The benefit of a quantitative measure of inequity like Gini was exemplified by comparing the Gini with that at the secondary canal and also against it if the tertiary canal could be operated "as designed". They found and suggested two new concepts: systematic and operational inequity. They also suggested that the costs of data acquisition could be reduced if this technology included in future development investments in large scale irrigation systems [7].

A study was conducted with the main objective to develop a Fuzzy Sarsa Learning (FSL) system for learning Operational Instructions which had prime role in increasing water delivery performance of irrigation canals. The developed FSL was tested on a canal by taking its physical and hydraulic data. The results depicted its reliability in terms of efficiency with respect to generalization and convenience of deployment. They found decreased in Total operational time from 23.1 hour in conventional operation to 5.76 hour in FSL [8].

A performance evaluation study was carried out by considering FSL method and Conventional Operation Methods for Water Delivery On-Request in the Aghili Network, Iran by taking same canal. According to results both methods were acceptable in terms of capability showing an efficiency of greater than $90 \%$ and the maximum water depth variation was less than $10 \%$, but FSL method gave more promising results and was able to distribute the water more uniformly in water shortage conditions [9].

A study was imitated using genetic algorithms model

Mehran University Research Journal of Engineering and Technology, Vol. 41, No. 1, January 2022 [p-ISSN: 0254-7821, e-ISSN: 2413-7219] 
to know problems of sequential irrigation scheduling. Under this study Four Genetic algorithms models were used by taking four different sequential irrigation scenarios to explore the efficiency of these models in solving scheduling problems. These models were tested widely for accuracy of problem solution by considering different size problems. The quality of the solution was compared with solution from integer programs and heuristics methods [10].

A field study of optimal operation scheduling of irrigation canals by means of genetic algorithm was initiated with the objective to identify the problem related to working schedule of irrigation canal with the capability of assigning time slots to outlets via Genetic Algorithm. Comparison with previously published operational schedule for the Famen secondary canal was carried out with the result indicated that this approach gave adequate relaxation in decision making by considering group formation of various outlets [11].

A study was conducted by using Genetic programming (GP) approach of grade-control structures for prediction of local scour downstream. The aim of this study was to provide a substitute conventional regression based equations and validate the dominancy of GP over regression analysis. the proposed GP formulation were based on well established and widely dispersed experimental results obtained from training and testing patterns of available literature. The GP based formulation results were more accurate and precise when compared with experimental results and other equations [12].

An Evaluation of irrigation scheduling problem by using genetic algorithm was started to facilitate a group of outlets. Before this work an integer program was applied to solve this problem but it belong to a class of combinatorial problems known as computationally demanding (N-P hard). It is used in operations research to solve relatively small problems where considerable computational resources and time could be allocated to solve a single schedule. This study highlighted the significance of robust testing of genetic algorithm developed to resolve irrigation scheduling problem with simultaneous outlets serviced beside an integer program developed to solve the identical problem [13].

A case study was started to see the water shortage impact on fair water allocation and land use of main irrigation projects. The results revealed that head reach portions got high supply in normal year, resulted peak risks of fluctuations in water supply while cropped area in a water deficit year compared to downstream portions had chronically low water supply but good adaptive responses by farmers. The conclusion suggested that fair distributions could be got by improving the water allocation efficiency of canal network in normal years while crop diversification and introduction of alternative water sources could be got in water deficit years [14].

The basic aim of study was to identify the main problems which would be helpful to solve very complicated and controversial problems in outlets of the Punjab. If all the outlets will be efficient then these will give more discharge of water. So, it will be advantageous for the irrigator. If the outlets draw a proper amount of silt then it will solve the problem of silting in the canals at which Government have to spend a large money and time. Legal procedure for theft is also included to have understanding for processing of cases. Irrigators always try to invent innovative methods of tampering, a few of these are also included in this paper so that to a plan to remove them. To obtain a Proportional distribution of water is very necessary in the Punjab canals so that an equal share of water can be achieved for each farmer. This study will be very helpful to solve the phenomenon of proportional distribution of water in the Punjab canals.

\section{SITE DESCRIPTION}

Punjab is an agriculture base province and about $80 \%$ population is associated with agriculture and related industries. Main source of agriculture is canal water. Canal system of Punjab is more than 100 years old, still unique system in the world. Punjab is land of five rivers named as Jehlum, Chenab, Ravi, Bias and Sutlej. This source of all river falls in India and after the independence of country in 1947, India disturbed the flow of the rivers as Head works of Upper reaches were in East Punjab. 


\section{OUTLETS IN PUNJAB}

\subsection{Old types of Outlets}

Oldest types of outlets which had been used in Punjab are given as follows.

- $\quad$ Tilted Pipe outlet

- Kennedy's cill outlet

- Kennedy's Gauge outlet

- Harvy Stoddard Improved outlet

- Kirkpatrick outlets

- Gibb's Module

- Ghaffoor's Rigid Module

\subsection{Commonly used types of outlets}

There are four types of outlets which are commonly used in Punjab.

- Open Flume Outlet

- Adjustable Orifice Semi-Module

- Pipe Outlet

- Scratchley Outlet

\section{DISCHARGE MEASUREMENT PROBLEM}

The Open Flume Outlet, AOSM, Pipe Outlet and Scratchley Outlet are the most common types of outlets used in the Punjab. These outlets are facing a lot of problems in which the main problems are following:

- Discharge measurement problems

- Tampering or theft

- Silting in canals

- Proportional distribution of water

All these problems are due to the fact that these are not properly designed. The outlets are mainly designed based on Designer experience than the site conditions, design criteria and use of suitable formula.

The outlet is a pivotal structure in irrigation network and plays a key role in proper distribution of the natural gift. The irrigation system in Pakistan is laid on a very mild slope and is upstream controlled. Further it is supply based and not demand based because of low quantum of available water. Therefore, outlet is only point at which the water can be measured/ controlled and delivered to the farmers which are in the hands of Irrigation Department and farmers are not involved in this activity. Therefore, proper design of outlet is of main concern which is the main theme of this paper for selection of right formula.

\subsection{Studying Discharge Measurement Problems}

Under the current study, the discharge measurement problems in the context of outlet design based on various types and formal have been studied. The results of calibration, allied issues and solutions are presented hereunder. Field measurements of a large number of outlets were taken. The data was analysed and calibration of the outlets was undertaken. The results are presented and discussed below.

\subsection{Calibrations of outlets}

Calibration of outlet is a good measure to check the accuracy of outlets. It has been found out by calibration of field outlet that there is lot of difference between authorized discharge and measured discharge. So, comprehensive efforts are required to adjust defective outlets as per their designed parameters. About 33 outlets were calibrated on 4-R Hakra distributary at Haroonabad from RD 59100 to $112050 \mathrm{RD}$ as given in Table No.1 and shown in Figs. 1(a), 1(b) and 1(c) for OF, OFRB and APM type outlets, respectively. Actual discharge was measured by Tin Flume as it is preferred to measure the discharge in watercourses by Tin Flume and compared with design/ theoretical discharges in Table 1.

The calibration was done for thirty-three (33) selected outlets for analysis, out of which nine (9) Adjustable Proportional Module (APM), seven (7) Open Flume and seventeen (17) OFRB were selected for calibration. Cd ranges were found $0.64-0.87$ for APM, $0.58-0.64$ for open flume and $0.41-0.86$ for OFRB, respectively which is less than 0.90 .

It is concluded from above observations that there was dramatic variation in $\mathrm{Cd}$ from their design value but not surprisingly when the complexities of outlets are considered. Many OFRB have less $\mathrm{Cd}$ because of the reasons: 


\begin{tabular}{|c|c|c|c|c|c|c|c|c|}
\hline \multicolumn{9}{|c|}{ Table 1: Field calibration of outlets along 4-R Hakra canal (59100/RD - 112050/RD) } \\
\hline WC & TYPE & $\mathrm{B}$ & $\mathrm{Y}$ & HU & Qth & Qac & Comments & $\mathrm{Cd}$ \\
\hline $59100 / \mathrm{R}$ & PIPE & 0.565 & & 1.04 & 2.84 & 1.73 & & 0.94 \\
\hline 59130 & OFRB & 0.3 & 1.368 & 2.06 & 5.4 & 3.46 & & 0.64 \\
\hline 60490 & APM & 0.3 & 0.58 & 1.87 & 1.91 & 1.59 & & 0.83 \\
\hline 62500 & PIPE & & & & & & Closed & \\
\hline 63910 & APM & 0.32 & 0.66 & 2.24 & 2.52 & 1.89 & & 0.75 \\
\hline 63910 & $\mathrm{OF}$ & 0.28 & & & & & Closed & \\
\hline 65080 & APM & 0.32 & 0.50 & 2.54 & 2.08 & 1.71 & & 0.82 \\
\hline 65080 & APM & 0.32 & 0.51 & 2.54 & 2.08 & 1.65 & & 0.79 \\
\hline 66050 & OF & 0.25 & & 2.43 & 3.8 & 2.93 & & 0.77 \\
\hline 67500 & PIPE & 0.47 & & & & & Closed & \\
\hline 69100 & PIPE & 0.661 & & & & & Closed & \\
\hline 69490 & PIPE & 0.23 & & 1.27 & 0.118 & 0.144 & & 1.22 \\
\hline 70640 & $\mathrm{OF}$ & 0.24 & & 2.17 & 3.185 & 2.58 & & 0.81 \\
\hline 71100 & PIPE & & & & & & Closed & \\
\hline 71270 & APM & 0.250 & 0.568 & 2.57 & 1.818 & 1.6 & & 0.88 \\
\hline 71735 & APM & 0.457 & 0.310 & 2.13 & 1.09 & 1.09 & & 1.00 \\
\hline 71750 & APM & 0.45 & 0.37 & 1.74 & 1.764 & 1.8 & & 1.02 \\
\hline 73600 & PIPE & & & & & & Closed & \\
\hline 73600 & PIPE & & & & & & Closed & \\
\hline 75366 & OFRB & 0.32 & 1.132 & 2.44 & 4.561 & 1.87 & & 0.41 \\
\hline 78400 & OFRB & 0.26 & 1.24 & 2.72 & 4.27 & 2.22 & & 0.52 \\
\hline 79224 & APM & 0.3 & 0.99 & 2.4 & 3.64 & 2.33 & & 0.64 \\
\hline 79230 & & & & & & & Closed & \\
\hline 81350 & OFRB & 0.24 & 1.25 & 2.43 & 3.74 & 1.72 & & 0.46 \\
\hline 86376 & OFRB & 0.31 & 1.365 & 2.39 & 5.26 & 3.05 & & 0.58 \\
\hline 87640 & OFRB & 0.24 & 1.265 & 1.64 & 3.1 & 1.52 & & 0.49 \\
\hline 88920 & APM & 0.25 & 0.61 & 3.025 & 2.14 & 1.71 & & 0.8 \\
\hline 89179 & APM & 0.38 & 0.55 & 3.2 & 2.98 & 2.6 & & 0.8 \\
\hline 91706 & PIPE & 0.250 & & 2.13 & 0.468 & 0.75 & & 1.6 \\
\hline 92631 & OFRB & 0.260 & 1.222 & 2.66 & 3.85 & 2.86 & & 0.69 \\
\hline 93870 & OFRB & 0.27 & 1.14 & 1.19 & 3.5 & 1.02 & & 0.55 \\
\hline 94300 & OFRB & 0.31 & 1.250 & 2.33 & 2.7 & 2.33 & & 0.86 \\
\hline 91102 & $\mathrm{OF}$ & 0.22 & & 1.77 & 2.36 & 1.49 & & 0.63 \\
\hline 95920 & PIPE & 0.765 & & 2.2 & 2.75 & 2.62 & & 0.95 \\
\hline 96362 & OFRB & 0.42 & 1.23 & 2.691 & 6.75 & 4.051 & & 0.6 \\
\hline 98729 & OFRB & 0.32 & 1.23 & 2.2 & 4.68 & 2.81 & & 0.6 \\
\hline 101069 & OFRB & 0.38 & 1.05 & 1.79 & 4.3 & 2.31 & & 0.54 \\
\hline 102214 & OF & 0.45 & & 2.25 & 2.31 & 3.17 & & 0.94 \\
\hline 102234 & OFRB & 0.49 & 0.82 & 1.526 & 3.98 & 2.15 & & 0.54 \\
\hline 104520 & OFRB & 0.44 & 0.97 & 2.244 & 5.09 & 3.156 & & 0.82 \\
\hline 105634 & OF & 0.3 & & 1.89 & 2.59 & 2.65 & & 1.02 \\
\hline 107020 & OFRB & 0.46 & 0.72 & 1.737 & 3.52 & 2.15 & & 0.61 \\
\hline 107022 & OFRB & 0.55 & 0.7 & 1.23 & 3.41 & 2.32 & & 0.68 \\
\hline 107055 & OFRB & 0.488 & 0.675 & 1.135 & 2.81 & 1.25 & & 0.48 \\
\hline 109980 & OFRB & 0.46 & 0.69 & 1.25 & 2.85 & 1.88 & & 0.66 \\
\hline 112000 & OF & 0.43 & & 1.21 & 1.33 & 1.88 & & 1.48 \\
\hline 112050 & OF & 0.76 & & 1.21 & 2.3 & 2.72 & & 1.20 \\
\hline
\end{tabular}

N.B.: $\mathrm{B}=$ width of the throat, $\mathrm{Y}=$ flow depth, Qac $\quad=$ actual discharge measured, $\mathrm{Qth}=$ design discharge and $\mathrm{HU}=$ Hydraulic depth upstream 


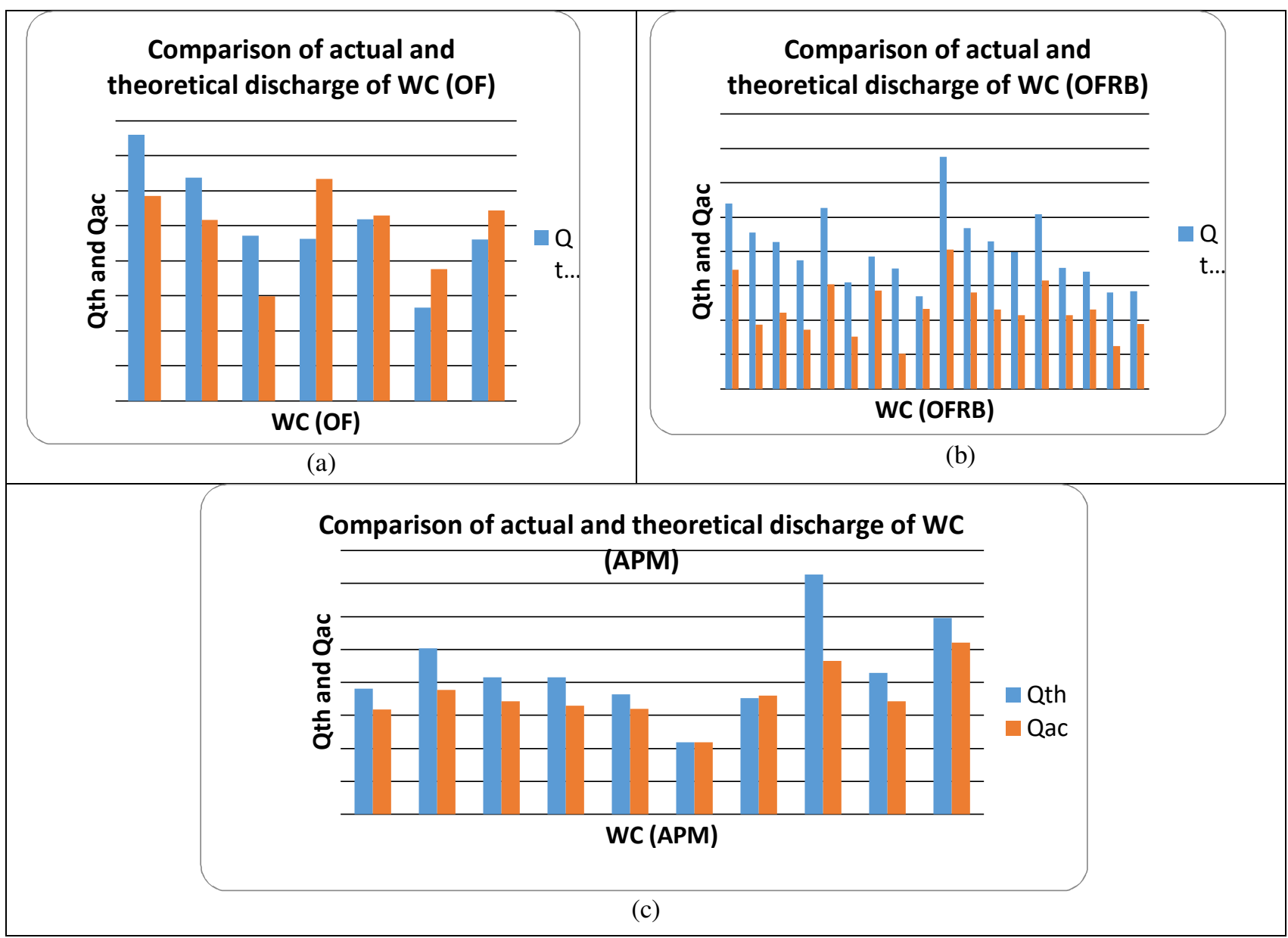

Fig.1: Field calibration of outlets along 4-R Hakra Canal for (a) OF, (b) OFRB and (c) APM

- Radius of $\mathrm{u} / \mathrm{s}$ transition is not proper.

- U/S face walls are not smooth.

- Roof black's lower edge is not proper.

- Turbulence is found out in control section.

- Setting back is not proper.

\subsection{Discussion On Discharge Formula of Adjustable Orifice Semi-Module (AOSM)}

The formula used for discharge measurement in A.O.S.M is small orifice formula which is given below.

$\mathrm{Q}=\mathrm{cd} \times \mathrm{A} \sqrt{2 \mathrm{gHs}}$

There are two types of orifices according to their size i.e. Small orifice and Large orifice. Large orifice is an orifice in which the head of water over the crest of orifice is less than five times the height of orifice. In case of large orifice, height of water over top edge of orifice (Hs) measured from the top of the orifice will not be true value, since the velocity will vary substantially from top to bottom of the opening.

The effect of both formulas of an outlet working under varying head of water $(\mathrm{Hs})$ over the orifice was observed as given in Table 2 and also shown in Fig. 2 as graphical representation between $\mathrm{Hs}$ and \% Error $(\% \mathrm{E})$ in discharge measurement. It was concluded from Figure 4 that by decreasing the Hs, \% error goes on increasing. From the analysis, it is inferred that the Hs should be atleast 3 times of orifice opening in order to keep the error in permissible limit. Therefore, this Fig. 2 was developed to observe the effect of both formulas on an outlet working under varying head of water over the orifice as \% Error versus Hs.

\subsection{Outlets as Means of theft of canal water}

Canal water is generally unauthorizedly used by following means; 


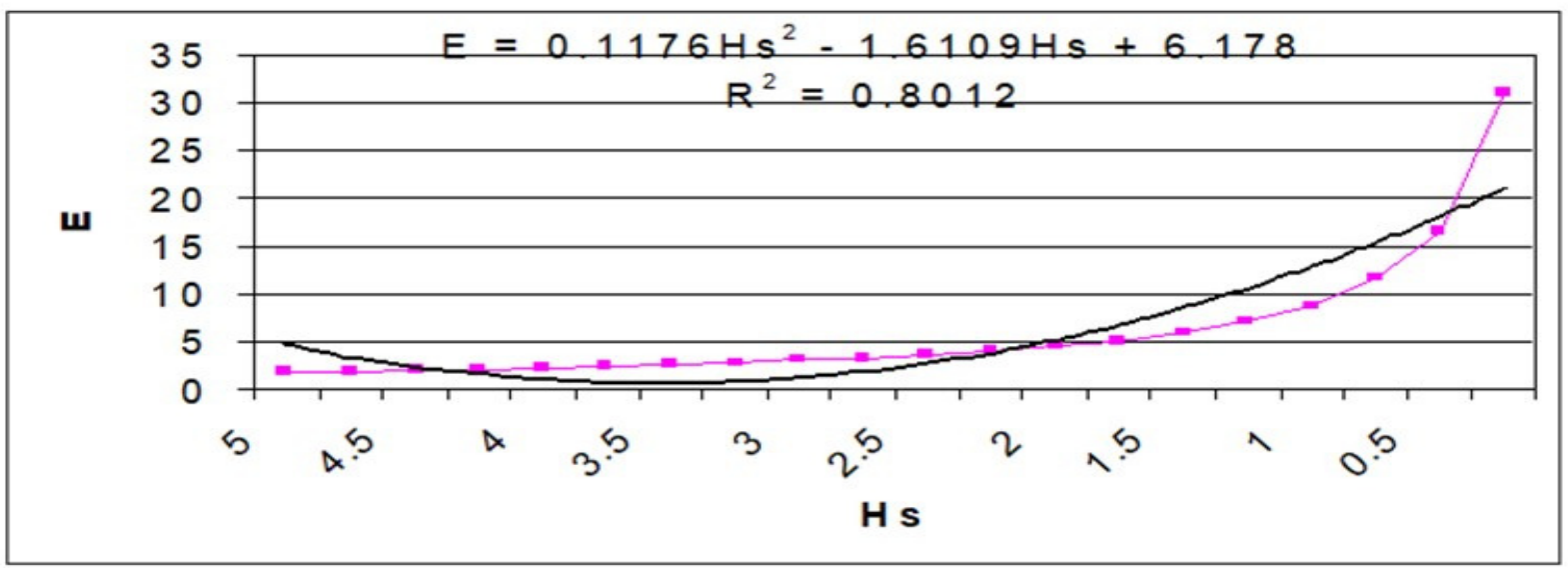

Fig. 2: Graphical Representation of Hs vs \% Error

- By siphon pipes.

- Fixing pipes in the bank.

- Tampering of outlets

- Cutting canal banks.

The following measures and precautions can minimize the theft of canal water if outlets are properly designed and placed;

- Outlets should be tamper-proof and any tampering should be easily detectable.

- Preparation and processing of tawan cases as per instructions laid down in the revenue manual of irrigation and power department as under:

- Preparation of preliminary cases in Zilldari offices (15days)

- Dak days from Zilladar's office to SubDivisional office (4days)

- Scrutiny of case in Sub-divisional officers' office to zilldari office ( 7days)

- Dak days from Sub-Divisional officer's office to Zilladar office (4days)

- Service of notice No1 in zilldari office (12days)

- Dak days from zilladari office to subDivisional office (4 days)

- Disposal of cases in Sub-Divisional office and final report (30days)

- Dak days from Sub-Divisional office to executive Engineer office (4days)

It means that total eighty (80) days is sufficient for
It means that total eighty (80) days is sufficient for preparation and processing of tawan cases. If the above schedule is followed divisional canal officer can decide the tawan cases with in the same crop time and may be implemented in the same khatoni. This action can realized the water thieves that they are accountable as criminal and penalable financially.

\subsection{Silting in Canals}

The silting in canals is a big problem not only for Irrigation Engineer but also for Irrigator. It can create a lot of problems i.e. Regime of the channel is disturbed, Capacity of the channel is reduced etc. In the Punjab alone at least five crores rupees are spent to clean the canals of only four hundred miles. The silting in the parent channel is due to:

- Faulty design of parent channel.

- Defective head regulator.

- Defective outlets.

However, the proper design and placement of outlets can help controlling the siltation issues. Silt conduction of the canal through outlet should be around $110 \%$ to $115 \%$. It can be achieved at a low setting of outlet so according to Sharma OF set at $9 / 10^{\text {th }}$ and AOSM set at $8 / 10^{\text {th }}$. But it is not in many cases to place the crest of outlet at or near the bed level on account of the practical difficulty of constructing Open Flume with Bt less than $0.2 \mathrm{ft}$. Similarly, on account of the limitations imposed by the available working head it is not possible to place the crest of 
AOSM at or near bed level.

With a high setting it is not possible for these Semimodules to take their fair share of the silt charge in the distributary. Various devices have been put forward to enable these outlets to draw more silt than they normally do such as Bend Outlet, Haigh's Silt Extracting SMMO, Pipe-cum-Semi-Module.

The semi-module pipe is extensively used in Haryaana, Punjab (India) and in Pakistan. This type of outlet can be regarded as a development of the Stoddard Harvey improved irrigation outlet. This type of outlet is highly suitable for supply canal with wide banks or high filing because an orifice semi-module or open flume outlet in such a bank would be much more expensive. This type of device is also used in lined canals. Further the outlet is appropriate for drawing its share of silt when it is not possible to achieve a deep setting. The lead-in pipe is placed at the bed level and it opens up into a tank on the downstream side to which an open flume or an orifice semi-module or scratchley outlet with free flow condition is fitted.

The Structural characteristics i.e. the outlet comprises of a lead-in pipe from the supply canal which discharges into a tank on the outer side of the bank. The upstream end of the lead -in pipe can be set at any appropriate level in the supply canal depending upon the desired silt draw. The downstream end of the leadin pipe may be horizontal or given an upward slope of about 1 to 12 to minimize tank depth. The tank is approximately $60 \mathrm{~cm}$ square for $30 \mathrm{l} / \mathrm{sec}$ discharge, 80 $\mathrm{cm} 2$ for $60 \mathrm{l} / \mathrm{sec}$ and $100 \mathrm{~cm}$ square for $90 \mathrm{l} / \mathrm{sec}$. A semi-module is also fitted in the downstream wall of the tank.

The Hydraulic characteristics of this outlet such as flexibility depends on the flexibility of semi-module incorporated with it except that its flexibility will be altered slightly means of the pipe between the tank and supply canal.

The outlet efficiency is determined by the type of Semi-module fixed to it and also depends on the loss of working head through the pipe. The amount of silt induction into the outlet depends only on the position of the pipe with respect to the bed; the crest of the semi-module can be placed at any level so that the loss in head through the pipe can be more than compensated for by a higher setting of the outlet. The discharge or the proportionality are not effected by position of the pipe and the pipe can be raised or lowered depending on the silt-dew requirements.

The formula designed for the size of the lead-in pipe is fixed so as to achieve a minimum loss of head, subjected to obtaining sufficient velocity in the pipe to convey silt form the supply canal. Numerous sizes of lead-in pipe for different discharges are given in Table 2 for guidance.

\begin{tabular}{|c|c|c|}
\hline \multicolumn{3}{|c|}{ Table 2: Various sizes of lead-in pipe for } \\
various discharges \\
\hline $\begin{array}{c}\text { Discharge } \\
\text { (1/sec) }\end{array}$ & \multicolumn{2}{|c|}{ Pipe Size } \\
\cline { 2 - 3 } & Width $(\mathrm{cm})$ & Height $(\mathrm{cm})$ \\
\hline Up to 35 & 30.5 & 30.5 \\
\hline 36 to 40 & 36.5 & 30.5 \\
\hline 41 to 45 & 43.0 & 30.5 \\
\hline 46 to 50 & 46.0 & 30.5 \\
\hline 51 to 55 & 46.0 & 38.0 \\
\hline 56 to 80 & 46.0 & 46.0 \\
\hline
\end{tabular}

Let $\mathrm{h}$ (l) be loss of head, then $\mathrm{h}$ (l) or $\mathrm{h}_{(\mathrm{wk}) 1}=926 \mathrm{q}^{2} / \mathrm{A}^{2} \mathrm{x}$

From this the water level in the tank can be determined as the FSL in the supply canal minus the loss of head through the pipe. The semi-module outlet can now be designed, the type depending on the head available and other conditions.

By a lower setting of outlet we can control the silt but it has its practical limitations as stated before. In this situation Pipe Semi-module offers a complete control over the silt induction by the outlet. It is necessary to remember that water course should be given as much silt as it can carry depending on the slope available in it. However, the low silt conduction capacity of some outlets should be compensated by giving more than their due share of silt to the other outlets, where conditions of commands permit to do so.'In cases, where it is not possible to dispose of all silt brought in the channel on account of constantly poor command on most of the outlets, the only solution is to raise the FSL. to increase the command that the total quantity of silt brought in is reduced. 


\subsection{Proportional Distribution of Water}

Proportional distribution on a canal system, if extended to outlets, creates serious difficulties in the working of the system. On some canals, however, the supplies available in the critical periods of agricultural rotation are so limited, that if distributaries are to be run only under full supply conditions, the periods of closure would be unduly long and crops would wither away in the interval.

There are two systems of supply which are Normal Irrigation System and Non-perennial systems. The Normal Irrigation System, Where the canals almost run with full supply level, a super-proportional distribution is more desirable than proportional. In such cases setting is kept high to make it hyperproportional in the head reach. This will help in damping out fluctuations in the supply of water $\mathrm{d} / \mathrm{s}$. whereas the Non-perennial systems, Where the canals run at full supply in the Kharif season and may have only 50\% supplies in the Rabi season, it is most essential to have proportional setting so that an equal amount of water is distributed at all times. Proportional setting for orifice semi module and open flume outlet is $0.9 \mathrm{D}$ and $0.6 \mathrm{D}$ respectively.

The ideal method of irrigation is to run a distributary system always with full supply but there is always variation of supply in the canal. This difficulty can be eliminated, and the proportional distribution required can be secured by the introduction of control points in a distributing channels. Where control points cannot be introduced, it is necessary to design outlets in such a manner that they are little affected by temporary or permanent changes in the regime of channels.

\section{CONCLUSIONS AND RECOMMENDATIONS}

On the basis of results presented and discussed above, it is concluded and recommended that;

\subsection{Conclusions:}

- The coefficient of discharge for various outlets differed from their specified values (i.e. 0.6 for 0.F. and 0.9 for AOSM outlets).

- Silting in the canals was also observed due to low velocities as a result of defective outlets.

- Pilfering of irrigation water is also a serious problem as $20 \%$ irrigation water in Rabi (OctMarch) while $40 \%$ in Kharif (Apr-Sep) season is stolen illegally. Proportional distribution of water depends on their setting

- Pipe Type Outlet of Pakistan could be successfully replaced by PVC. Pipe Turnout (Korea).

- Many types of outlets which were successfully used in the World couldn't be adapted in Pakistan due to their Modular or Non-Modular behavior and no control over silt conduction and high installation cost.

- Plastic Siphon Outlet could be successfully used in Potohwar region of Pakistan where slopes were so steep that dynamic velocity head could be successfully utilized for lift irrigation.

- Calibration of the Outlets in Pakistan should be the regular feature of Irrigation Department Staff routine activities as it indicates the problems of the outlets.

- Irrigation efficiency of the Outlets could be increased by proper designing of outlets.

- In order to keep percentage error within a permissible limit as in case of AOSM it is advantageous to use the water depth on the top edge of the orifice more than three times the depth of orifice.

- Higher setting of outlets should be preferred in perennial canals while proportional setting should be preferred in non-perennial canals.

\subsection{Recommendations}

- Recommendation will be made to draw silt from canals having higher setting of outlets. The Irrigation department should spend a large amount of money for dredging operation by shutting down the canals for some period.

- Pipe Semi Module is the best choice if we cannot keep a lower setting of the outlet for proper silt control.

- The tail reaches of the canals should closely be monitored by the Irrigation Department as these are indicators of theft in the canal system. 


\section{NOTATIONS}

$\begin{array}{lll}\mathrm{B} & = & \text { width of the throat } \\ \mathrm{Y} & = & \text { flow depth } \\ \mathrm{Qac} & = & \text { actual discharge measured } \\ \mathrm{Qth} & = & \text { design discharge } \\ \mathrm{HU} & = & \text { Hydraulic depth upstream } \\ \mathrm{Hs} & = & \begin{array}{l}\text { Height of water over top edge of } \\ \text { orifice. }\end{array} \\ \mathrm{APM} & = & \text { Adjustable Proportional Module } \\ \mathrm{AOSM} & = & \text { Adjustable Orifice Semi-Module } \\ \mathrm{cd} & = & \text { Coefficient of discharge } \\ \mathrm{A} & = & \text { Cross-sectional area of flow } \\ \mathrm{OF} & = & \text { Open Flume }\end{array}$

\section{ACKNOWLEDGEMENT}

The staff of Irrigation Department Punjab Lahore and International Irrigation Management Institute Lahore, Pakistan and their high level Officers is highly acknowledged for their coordination and cooperation in facilitation of this work and collection of data.

\section{REFERENCES}

1. Sharma U., Mahesh K., Yogita D., "Performance Assessment of Water Delivery and Distribution in Som Kamla Amba Irrigation Scheme", Irrigation and Drainage, Vol. 68, No.2, pp.227-233, 2019.

2. Zema D.A., Angelo N., Santo M. Z., "Improving management scenarios of water delivery service in collective irrigation systems: a case study in Southern Italy", Irrigation science, Vol. 37, No.1, pp.79-94, 2019.

3. Raghuwanshi R., Khalkho D., Katre P., Tripathi M.P., Raghuwanshi N.S, "Design of gravity flow underground pipe distribution network in the canal command area", Indian Journal of Soil Conservation, Vol. 46, No.2, pp.218-224, 2018.

4. Mehare J., Rushabh G., "Economics of Pipe Distribution Network over Canal Distribution Network by Optimal Utilization of water", Economics, Vol. 4, No.11, pp.181-183, 2018.

5. Rajput J., Kothari M., Bhakar S.R.,"Performance Evaluation of Water Delivery System for Command Area of Left Main Canal of Bhimsagar
Irrigation Project, Rajasthan", Journal of Agricultural Engineering, Vol. 54, No.3, pp.5766, 2017.

6. Nam W.H., Hong E.M, Choi J.Y., "Assessment of water delivery efficiency in irrigation canals using performance indicators", Irrigation science, Journal of Agricultural Engineering, Vol. 34, No.2, pp.129-143, 2016.

7. Shah M.A.A., Anwar A.A., Bell A.R., Haq Z., "Equity in a tertiary canal of the Indus Basin Irrigation System (IBIS)", Agricultural Water Management, Vol. 178, No.2, pp. 201-214, 2016.

8. Kazem S., Monem M.J and Nili M., "Fuzzy SARSA learning of operational instructions to schedule water distribution and delivery", Irrigation and Drainage, Vol.65, No.3, pp.276-284, 2016.

9. Savari H., Monem M.J., Shahverdi K., "Comparing the Performance of FSL and Traditional Operation Methods for On-Request Water Delivery in the Aghili Network, Iran", Journal of Irrigation and Drainage Engineering, Vol. 142, No.11, 04016055, 2016.

10. Anwar A.A., Haq Z., "Genetic algorithms for the sequential irrigation scheduling problem", Irrigation Science, Vol. 31, No.4, pp.815-829, 2013.

11. Mathur. Y.P., Sharma G., Pawde A.W., "Optimal operation scheduling of irrigation canals using genetic algorithm", International Journal of Recent Trends in Engineering, Vol. 1, No.6, pp.11-15, 2009.

12. Guven A., Gunal M., "Genetic programming approach for prediction of local scour downstream of hydraulic structures", Journal of Irrigation and Drainage Engineering, Vol. 134, No.2, pp.241-249, 2008.

13. Haq Z., Anwar A.A., Clarke D. "Evaluation of a genetic algorithm for the irrigation scheduling problem", Journal of Irrigation and Drainage Engineering, Vol. 134, No.6, pp.737-744, 2008.

14. Gaur A., Biggs T.W., Gumma M. K., Parthasaradhi G., Turral H., "Water Scarcity Effects on Equitable Water Distribution and Land Use in a Major Irrigation Project-Case Study in India", Journal of irrigation and drainage engineering, Vol. 134, No.1, pp.26-35, 2008. 